\title{
Calibration of Estimates on Direct Wildfire Emissions from Remote Sensing Data
}

\author{
E. I. Ponomarev ${ }^{a, b}$, *, E. G. Shvetsov ${ }^{a}$, and K. Yu. Litvintsev ${ }^{c}$ \\ ${ }^{a}$ Sukachev Institute of Forest, Siberian Branch, Russian Academy of Sciences, Federal Research Center KSC SB RAS, \\ Krasnoyarsk, Russia \\ ${ }^{b}$ Joint Regional Center for Remote Sensing, Federal Research Center KSC SB RAS, Krasnoyarsk, Russia \\ ${ }^{c}$ Kutateladze Institute of Thermophysics, Siberian Branch, Russian Academy of Sciences, Novosibirsk, Russia \\ *e-mail:evg@ksc.krasn.ru \\ Received December 12, 2017
}

\begin{abstract}
This study is based on the processing of satellite imagery in the wave range 3.93-3.99 $\mu \mathrm{m}$ (Terra/Modis satellite) and numerical simulation results. It has been found for combustion conditions in Siberian forests that the observed fire radiative power (FRP) is $15 \%$ of the total fire power. Variations between 10 and $30 \%$ depend on both the fire development scenario (specific burnup rate of $0.01-0.1 \mathrm{~kg} / \mathrm{m}^{2} \mathrm{~s}$ and fire front velocity of $0.01-0.1 \mathrm{~m} / \mathrm{s}$ ) and the conditions for remote imaging. Instrumental estimates for the ratio of fire areas by given intensity quantiles for Siberian forests are presented. The share of low-, medium-, and high-intensity fires is $41.2-58.9,35.0-46.5$, and $6.10-13.44 \%$ of the total area. Refined estimates of fire emissions have been obtained taking into account the amount of biomass burnt and variable burning intensity. The proposed method allows the mass of burned forest fuel materials (FFM) and direct fire emissions to be estimated quantitatively at a level 14-21\% lower than the values calculated with the help of standard approaches. The estimates of direct carbon emissions in the given time interval of 2002-2016 were $83 \pm 21 \mathrm{Tg} / \mathrm{year}$ on average, which is $17 \%$ lower than the value $112 \pm 25 \mathrm{Tg} /$ year obtained with the standard method.
\end{abstract}

Keywords: remote sensing data, active burning zone, fire radiative power, intensity, fuel combustion completeness, emission

DOI: $10.1134 /$ S0001433819090408

\section{INTRODUCTION}

Data available on vegetation fires, including longterm instrumental satellite observations, allow one to fix a significant trend of fire activity growth in Siberia (Ponomarev and Kharuk, 2016). According to annual fire statistics of Russia, the forest fires in the Siberian boreal zone are predominant: 70-90\% of total annual burned area. As the most significant factor of forest degradation, the Siberian fires largely determine the carbon balance on a planetary scale. According to forecasts, the pyrogenic carbon emissions in Siberia, which currently amount to $120-140 \mathrm{Tg}$ /year (Bondur et al., 2016; Shvidenko et al., 2011; Soja et al., 2004), may increase twofold to $240 \mathrm{Tg} /$ year in the second half of the 21st century (Zamolodchikov et al., 2011).

At present, the problem of instrumental quantitative estimates for fire emissions is not reliably solved. A number of studies discuss both the direct emission estimates (Bondur et al., 2016; Baldocchi et al., 2017; Conard et al., 2002; Ivanova et al., 2007; Shvidenko et al., 2011; Yurova et al., 2013) and the factors limiting the accuracy of the results (Glagolev and Sabrekov, 2014; Kukavskaya et al., 2013; McRae et al., 2006;
Ponomarev and Shvetsov, 2015; Soja et al., 2004;). Existing approaches allow one to obtain qualitative estimates and averaged extrapolated data without the ability to instrumentally determine and take into account the differences in combustion parameters for each fire site. In view of the scale of fire processes both around the world and at the regional level (in Siberia), the development of approaches to make estimates on the basis of remote satellite methods is both important and promising (Ichoku and Kaufman, 2005; Safronov et al., 2015; Vermote et al., 2009).

This study addresses the development of methods for a quantitative estimation of direct emissions from fires. We propose using the remote monitoring data processed to determine the energy characteristics of fires and the subsequent classification of burned areas from the level of burning intensity. The main goal of this study is to develop a method for determining the amount of burned forest fuel materials (FFM) and to calibrate the estimates of fire emissions on the basis of remotely recorded parameters of the active zone of fires.

In this regard, we have considered the following aspects of the problem: (1) analysis of the recorded 
combustion parameters coupled with fire scenarios, (2) classification of fire areas by intensity, and (3) characterization of the accuracy of quantitative estimates of burned forest fuel materials and direct fire emissions.

\section{INITIAL DATA AND METHODS Research Area}

In this study, we consider all the Siberian forest fires that are spatially localized within $50^{\circ}-67^{\circ} \mathrm{N}$, $60^{\circ}-150^{\circ} \mathrm{E}$. The study area includes the main forest regions of Siberia: the Middle Siberian Plateau (a taiga forest region), the Angara forest region, the West Siberian plain marshland-taiga region, the Trans-Baikal mountain forest region, the East Siberian taiga permafrost, and the East Siberian region of tundra forests and light taiga.

\section{Fire Data}

The analysis was based on the forest fire database of the V.N. Sukachev Institute of Forest, Siberian Branch, Russian Academy of Sciences, Federal Research Center KSC SB RAS (Ponomarev and Shvetsov, 2015; Sukhinin, 1996). The source data were obtained from processed NOAA/AVHRR, Terra, and Aqua/Modis satellite imagery from 1996 to 2016. The database contains more than $2 \times 10^{6}$ records for the Asian part of the Russian Federation.

The sample used in the analysis is statistically significant and included 985 fire polygons with a predominance of dark conifers, 424 in deciduous, 1646 in pine, and 4339 in larch stands for 2002-2016. The areas of the considered fire polygons were 1000 ha or more due to limitations imposed by the spatial resolution $(1000 \mathrm{~m})$ of the initial data on the further polygon classification. Each fire polygon was assigned an attribute characterizing its belonging to the prevailing forest stand (Bartalev et al., 2011) on the basis of geoinformation (GIS) combination of the fire layer and the vegetation map layer.

The data on the radiation power of active burning zones were taken from the MOD14/MYD14 product (Giglio, 2013) collection 5 obtained from the Modis radiometer (from Terra and Aqua satellites) for 20022016. The integral signal generated by the active burning zone was calculated from calibrated imagery in the mid-IR range (21 channels of the Modis radiometer in an operating range of 3.93-3.99 $\mu \mathrm{m}$ ) from Terra and Aqua satellites-MOD 14 and MYD14 products, respectively. A technique for calculating the Fire Radiative Power (FRP), which characterizes the power of heat radiation and the combustion intensity (Wooster et al., 2005; Kumar et al., 2011), was used. The technique for calculating the radiation power at the fireline according to combined data of a wide range of radiometer channels (operating ranges of 4 and $11 \mu \mathrm{m}$ ) is based on the bispectral method (Dozier, 1981). The combustion intensity at the fireline was calculated using well-known approaches (Byram, 1959) taking into account FRP data.

Normalization to the actual pixel area calculated according to the formulas given in (Ichoku and Kaufman, 2005) was performed taking into account possible geometric distortions to normalize the overestimated heat radiation. Thus, the initial data were converted to heat-radiation power per unit area.

\section{Forest Fuel Loads}

Estimates of forest fuel loads for individual territories of the research area were generalized from data of the studies (Tsvetkov, 2005; Kurbatsky and Ivanova, 1987; Volokitina and Sofronov, 2002; Andreev et al., 2015; de Groot et al., 2013; Ivanova et al., 2007, 2016; Valendik et al., 2006). At the stage of numerical modeling, a generalized indicator was used an input parameter, characterizing the amount of on-ground cover with a predominance of larch, pine, dark coniferous, and deciduous stands.

Further, the heat-radiation power measured in the mid-IR range was taken to be linearly related to the amount of burned biomass (Wooster et al., 2005). Thus, the amount of burned vegetation was analytically calculated as well, using heat radiation from the active burning zone (FRP) as input data.

\section{Numerical Simulation}

An unsteady model fire was calculated using authorial SigmaFire software package (certificate no. 2010613073) based on computational fluid dynamics and heat- and mass-transfer methods. The model fire is based on two main empirical characteristics: burnout rate and flame-front propagation velocity. Varying these parameters made it possible to evaluate the potential effect of fire intensity on the radiation power recorded by the satellite. To solve these tasks, we developed a simplified model of conjugate heat transfer that includes one-dimensional heat transfer in the solid phase. To calculate the coefficient of radiation absorption in the gas phase, we used the "gray gas" approximation on the basis of the Weighted Sum of Gray Gases (WSGG) model (Smith et al., 1982), which describes the gas combustion of hydrocarbon fuels rather well. A two-parameter Menter's Shear Stress Transport (M-SST) model of turbulence was used to describe the turbulent flow (Menter, 1993).

\section{Methods for Calculating the Amount of Burned Biomass and Direct Emissions}

To calculate the amount of burned biomass and to estimate direct carbon emissions, one normally uses the technique (Seiler and Crutzen, 1980) 


$$
\begin{gathered}
M=A \times \beta \times B, \\
C=A \times \beta \times B \times C E,
\end{gathered}
$$

where $M$ is the mass of forest fuel burned during the fire $(\mathrm{kg}), C$ is direct carbon emissions $(\mathrm{g}), A$ is the burned area $\left(\mathrm{m}^{2}\right), \beta$ is the coefficient of combustion completeness, $B$ is the prefire forest fuel load $\left(\mathrm{kg} / \mathrm{m}^{2}\right)$, and $C E$ is a coefficient for the fraction of carbon in the burning biomass $(\mathrm{g} / \mathrm{kg})$.

Based on remote measurements of heat release from the active combustion zone and on empirical coefficients, one can calculate the intensity of fuel combustion (Wooster et al., 2005):

$$
V_{\mathrm{br}}=0.358( \pm 0.015) \times F R P,
$$

where $V_{\mathrm{br}}$ is the mass burnup rate $(\mathrm{kg} / \mathrm{s}), F R P$ are the values of heat radiation (MW) recovered from satellite measurements in the range of 3.93-3.99 $\mu \mathrm{m}$, and $0.358( \pm 0.015)(\mathrm{kg} / \mathrm{J})$ is an experimentally obtained coefficient (Wooster et al., 2005).

From (3), one can obtain the fraction of FRP in the integral fire power:

$$
F R P / Q=1 /(0.358 q),
$$

where $Q$ is the integral fire power (MW) and $q$ is the specific heat of combustion $(\mathrm{MJ} / \mathrm{kg})$.

This approach is also applicable for alternative estimates of fire emissions (Safronov et al., 2015). However, the empirical nature of the coefficients used in relation (3), which were originally obtained by the authors only for experimental conditions (Wooster et al., 2005), limits its direct use. For example, the case of Siberian forest fires with widely varying parameters requires a calibration of the coefficients for all variants of forest growth and fire conditions. Therefore, in this study, the FRP indicator was analyzed to classify the fires and individual zones in terms of the combustion intensity rather than used to directly calculate the amount of burned biomass and emissions.

\section{Differential Accounting for Fire Areas}

The required estimates of the amount of burned biomass and direct emissions were refined by the differential accounting for differences in the combustion parameters within each of the active burning zones distinguished instrumentally. Specifically, the parameter $A\left(\mathrm{~m}^{2}\right)$ in relations (1) and (2) was represented as the sum of the areas of all fires recorded by satellite imagery taking into account the combustion intensity $A_{i}\left(F R P_{i}\right)$ :

$$
A=\sum_{i} A_{i}\left(F R P_{i}\right)
$$

The threshold method was used to classify fire pixels with identified categories of combustion intensity. The threshold values identifying the categories were determined from statistical parameters of the radiation power distribution calculated for all fire pixels. This was performed by excluding $5 \%$ of the minimum and maximum values of the power and the average and standard deviation were calculated over the remaining sample. The intensity quantiles were given with respect to the standard deviation from the average: quantiles I, II, and III corresponded to fire areas with $F R P<F R P_{\mathrm{av}}-\sigma, F R P_{\mathrm{av}}-\sigma<F R P<F R P_{\mathrm{av}}+\sigma$, and $F R P>F R P_{\mathrm{av}}+\sigma$, respectively. The ranges of radiation power (intensity quantiles) were used to identify the fire polygon areas corresponding to low-, medium-, and high-intensity combustion sections.

For each section $A_{i}\left(F R P_{i}\right)$, the amount of forest fuel burned during the fire was estimated using relation (1) and variable coefficients of complete combustion $\beta$. The value of $\beta$ was obtained depending on the intensity quantile from model values $\beta=\beta\left(F R P_{i}\right)=0.35-0.60$ (Tsvetkov, 2005; Glagolev and Sabrekov, 2014).

Then, we calculated the relative deviation refining the estimates for the amount of burned fuel depending on the fire category in terms of area and intensity from the relation

$$
\Delta M_{\text {rel }}=100 \times\left(M-M_{d}\right) / M,
$$

where $\Delta M_{\text {rel }}$ is the relative deviation, $M$ is the amount of burned fuel calculated with technique (1), and $M_{d}$ is the amount of fuel calculated with the differential approach taking into account (4).

Thus, for each section, the number of fuel burned at a given fire intensity was calculated. The total amount of fuel combusted within each fire polygon was calculated by summing the values for all sections contained in the polygon. The estimates obtained in this way were compared with the values calculated without the differential approach, i.e., using the same values of the coefficient of combustion completeness and fuel load within the entire fire polygon.

Then, we recalculated the direct emissions $(C)$ using (1) taking into account the data of (4). The relative deviation was determined similarly from (5).

\section{RESULTS AND DISCUSSION Ratio of Fire Areas}

FRP corresponds to the dynamics of the active burning zone in different observation periods. The radiation powers in most of the measurements (up to $88 \%$ of their total number) did not exceed $50 \mathrm{MW} / \mathrm{km}^{2}$. The average value for the reliability level of $95 \%$ was $37.4 \mathrm{MW} / \mathrm{km}^{2}$ $\left(\sigma=17.1 \mathrm{MW} / \mathrm{km}^{2}\right)$. Two threshold values for intensity quantiles were obtained: 20.3 and $54.5 \mathrm{MW} / \mathrm{km}^{2}$.

Based on the ranges of radiation power (intensity quantiles), we classify the fire polygon areas corresponding to low-, medium-, and high-intensity combustion sections (Table 1).

The resulting ratios of fire areas were conjugated using GIS according to intensity quantiles with the prevailing forest stands coupled to the Siberian forest 
Table 1. Results of processing of data on the ratio of areas fires of varying intensity recorded in Siberian forests in $2002-2016$

\begin{tabular}{|c|c|c|c|c|c|c|c|}
\hline \multirow{3}{*}{ Prevailing tree stand } & \multicolumn{6}{|c|}{ Share of total fire area } & \multirow{3}{*}{$\begin{array}{c}\text { Number } \\
\text { of sample polygons }\end{array}$} \\
\hline & \multicolumn{2}{|c|}{ Low intensity } & \multicolumn{2}{|c|}{ Medium intensity } & \multicolumn{2}{|c|}{ High intensity } & \\
\hline & $\%$ & $\sigma$ & $\%$ & $\sigma$ & $\%$ & $\sigma$ & \\
\hline Larch & 42.28 & 15.8 & 46.04 & 11.48 & 11.68 & 7.88 & 4339 \\
\hline Pine & 43.67 & 15.48 & 44.60 & 11.26 & 11.73 & 8.48 & 1646 \\
\hline Dark coniferous & 47.32 & 12.76 & 41.74 & 8.00 & 10.94 & 7.1 & 985 \\
\hline Deciduous & 43.64 & 17.25 & 42.92 & 13.20 & 13.44 & 10.15 & 424 \\
\hline $\begin{array}{l}\text { Without consideration } \\
\text { of stands }\end{array}$ & 47.04 & 13.6 & 42.46 & 10.50 & 10.50 & 6.90 & 7394 \\
\hline
\end{tabular}

regions (Fig. 1). The analysis showed that the areas of low-, medium-, and high-intensity fires were 41.2$58.9,35.0-46.5$, and $6.10-13.44 \%$ of the total area, respectively. The variation at the level of $\sigma=13.6,10.5$, and $6.9 \%$ is determined by differences in fire danger scenarios in the given seasons of 2002-2016. With an increase in the total area of the fire polygon, a decrease in the fraction of low-intensity combustion areas was observed, while, at the same time, the area of areas with medium and high values of heat-radiation power tended to increase (Fig. 2). The linear regression coefficients $k<0$ for low-intensity fires in larch, dark coniferous, and deciduous forests and $k>0$ for all variants of medium- and high-intensity fires. This regularity is
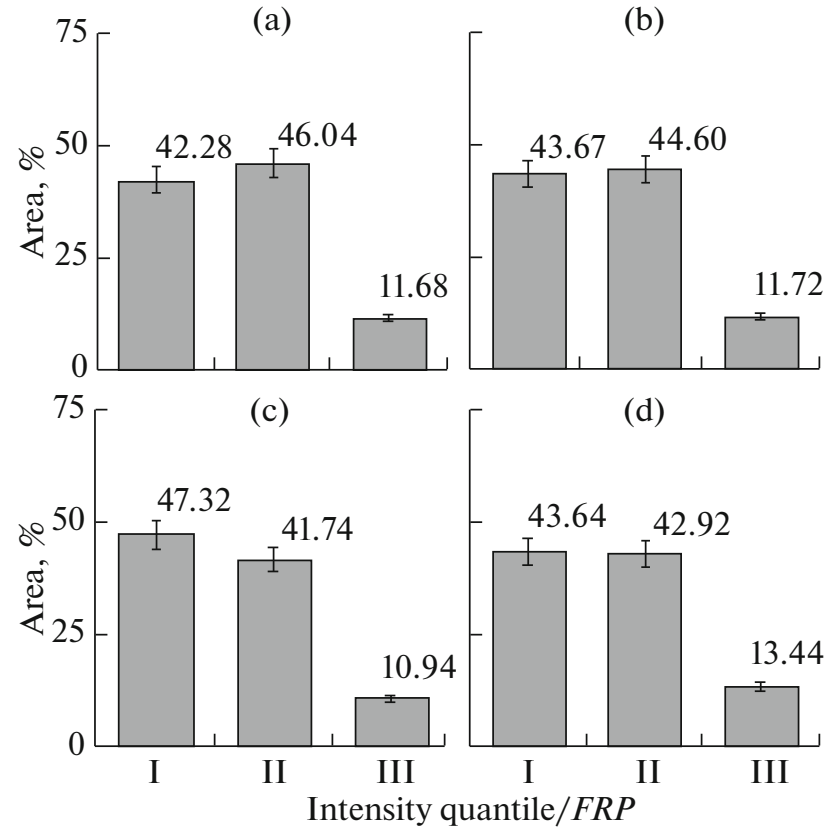

Fig. 1. Ratio of burned areas of variable intensity in Siberian forests with a predominance of (a) larch, (b) pine, (c) dark coniferous stands, and (d) deciduous/mixed stands. The intensity quantiles are identified with respect to $F R P$ : (I) $<F R P_{\mathrm{av}}-\sigma$, (II) from $F R P_{\mathrm{av}}-\sigma$ to $F R P_{\mathrm{av}}$, and (III) $>F R P_{\mathrm{av}}+\sigma$. less true for the analysis of fire distributions in pine stands, where the fraction of low-intensity burning sites stays unchanged $(k=-0.84)$, depending on the total fire area (Fig. 2a).

The instrumental estimate for the ratio of the areas burned by fires of different intensities for Siberia was obtained for the first time. Earlier studies usually reported empirical data at levels of 22.0, 38.5, and $38.5 \%$ for low-, medium-, and high-intensity fires, respectively (Soja et al., 2004).

In this case, it was previously established by us (Ponomarev et al., 2017) that satellite tools can be used to confidently detect part of high-intensity fires classified as crown fires; the area of this category reaches $8.5 \%$ of the area of fire damage in Siberian forests.

There are few works presenting data on the attribution of fires to the species composition of forests in modern Siberia or Russia as a whole. Actual estimates made by instrumental (satellite) tools can be found in (Bartalev et al., 2015), where the fraction of fire areas in larch (up to $50 \%$ of the total), dark coniferous (almost $5 \%$ ), and light coniferous and deciduous (18 and 19\%, respectively) forests are given, which is consistent with the results obtained by other authors (de Groot et al., 2013; Ponomarev et al., 2016; Soja et al., 2004).

The results presented in our study are valid for the most common forest stands of Siberia (particularly, with a predominance of larch, pine, dark coniferous, and deciduous stands). Due to the prevalence of these forests in Siberia, at least $80-85 \%$ of all burned areas per year are annually recorded in them. Thus, the quantitative details obtained by us for fire areas in Siberia for the first time significantly supplements and elaborates the variability of the extent of disturbed forests taking into account the effects of fires of variable intensity.

\section{Recorded Heat Radiation and Fire Parameters}

The thermal radiation of fires and the radiation intensity depend on surface temperature and smoke particles. The signal recorded by the radiometer in the range of 3.93-3.99 $\mu \mathrm{m}$ and the subsequent FRP calcu- 
lations depend on the fire scenario and the imaging conditions.

In this study, we performed a numerical simulation of the relationship of $F R P$ values with the parameters of the active burning zone. In relation to the estimates of direct fire emissions, surface fires with a share of at least $92-95 \%$ in Siberia make the largest contribution. In model calculations, the values of the specific burnup rate varied in the range of $0.01-0.1 \mathrm{~kg} / \mathrm{m}^{2} \mathrm{~s}$ and the flame front propagation rate varied in the range of $0.01-0.1 \mathrm{~m} / \mathrm{s}$. For the given parameters, the numerical experiment showed that the recorded $F R P$ on average is $15 \%$ of the integral fire power, which is very consistent with the results presented in (Wooster et al., 2005). Indeed, according to formula (3a), for specific heat of fuel combustion $q=17 \mathrm{MJ} / \mathrm{kg}$ (used in the model fire), the ratio of $F R P$ to the integral fire power is $16.4 \%$. In general, the calculated value of the recorded radiation power was between 10 and $30 \%$ of the integral power of heat generation in the active zone. In addition, an analysis of the first results of the numerical simulation indicated that there is a tendency toward an increase in the $F R P$ fraction with an increase in the flame-front propagation rate.

The resulting estimates made it possible to analytically (based on model equations (Byram, 1959; Wooster et al., 2005)) obtain the dependence of FRP variation on fire parameters (Fig. 3). For example, an increase in the specific burnup rate of fuel $\left(\mathrm{kg} / \mathrm{m}^{2} \mathrm{~s}\right)$ doubles the range of recorded $F R P$ values with a shift of the maximum from $75-100 \mathrm{MW}$ per pixel to $200 \mathrm{MW}$ or more (Fig. 3a). Here, the subpixel value of the active combustion area within the active pixel was taken into account (Dozier, 1981). Also, a quantitative description was obtained for the dependence of FRP on the front propagation rate (Fig. 3b), the fuel reserves in the active combustion zone $\left(\mathrm{kg} / \mathrm{m}^{2}\right)$, and the coefficient of combustion completeness $(\beta)$. The resulting range of the values of combustion completeness is consistent with the results of the experimental observations, where $\beta$ varies in a wide range of $0.35-0.60$ (Tsvetkov, 2005; Glagolev and Sabrekov, 2014).

\section{Calculation of the Amount of Burned Biomass and Direct Carbon Emissions}

The calculation of the amount of burned forest fuel materials (FFM) and direct calculations of emissions were conducted using (1), (4), and (5). The required data on fuel reserves was generalized from studies where the amounts of fuel reserves for larch, pine, dark coniferous, and deciduous stands of Siberia varied at $1.38-5.4 \mathrm{~kg} / \mathrm{m}^{2}$ (Tsvetkov, 2005; Kurbatsky and Ivanova, 1987; de Groot et al., 2013; Ivanova et al., 2016; Valendik et al., 2006). It was also taken into account that the empirical estimates for fuel reserves in fires of different intensities vary at $0.11-0.97,0.86-$ 2.15 , and $2.25-5.36 \mathrm{~kg} / \mathrm{m}^{2}$ for low-, medium-, and (a)
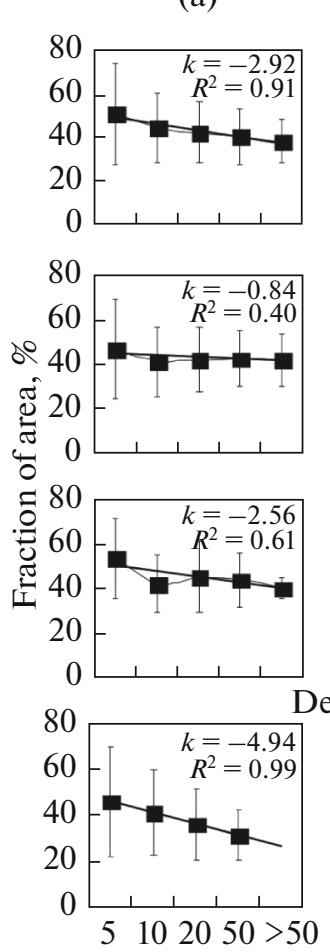

(b)

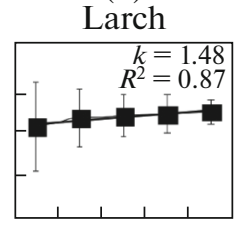

Pine

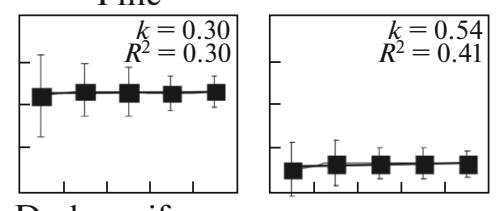

Dark coniferous

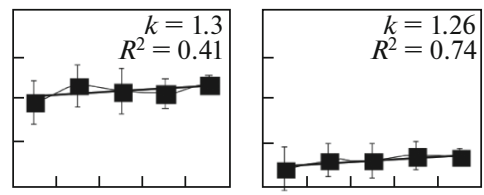

Deciduous and mixed
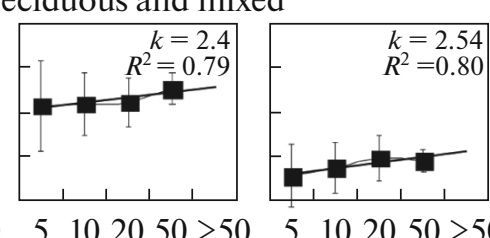

Fire category, thousand ha

Fig. 2. Ratio of areas burned by fires of low (a), medium (b) and high (c) intensity, depending on fire category by the total area (thousands of hectares). Data on Siberian fires in larch, pine, dark coniferous, and deciduous/mixed forests for 2002-2016.

high-intensity combustion, respectively (Conard et al., 2002; Kasischke and Bruhwiler, 2003; Soja et al., 2004). The coefficient of combustion completeness varied depending on the intensity quantile. For example, $\beta$ was taken to be in the range of $0.35-0.40,0.40-0.45$, and $0.45-0.5$ for low-, medium, and high-intensity fires, respectively.

The differential approach used for the areas burned by fires of variable intensity mostly allowed us to quantify the mass of burned fuel $(M)$ and direct emissions of fires $(C)$ 14-21\% lower than the results of calculations obtained with standard approach (1) and (2). Under Siberian conditions, this depends on the predominance of areas burned by low-intensity fires, which was also noted in related studies (de Groot et al., 2013; Soja et al., 2004).

In $93 \%$ of cases, the proposed method recorded lower masses of burned fuel; in only $7 \%$ of cases were they the same or exceeded the results of calculations by standard method (1). The same can be stated about the estimates of direct fire emissions $(C)$, which directly depend on the accuracy of methods for estimating the burned fuel mass. In the calculated series of data, the absolute deviations of $\Delta M$ and $\Delta C$ decreased 
(a)

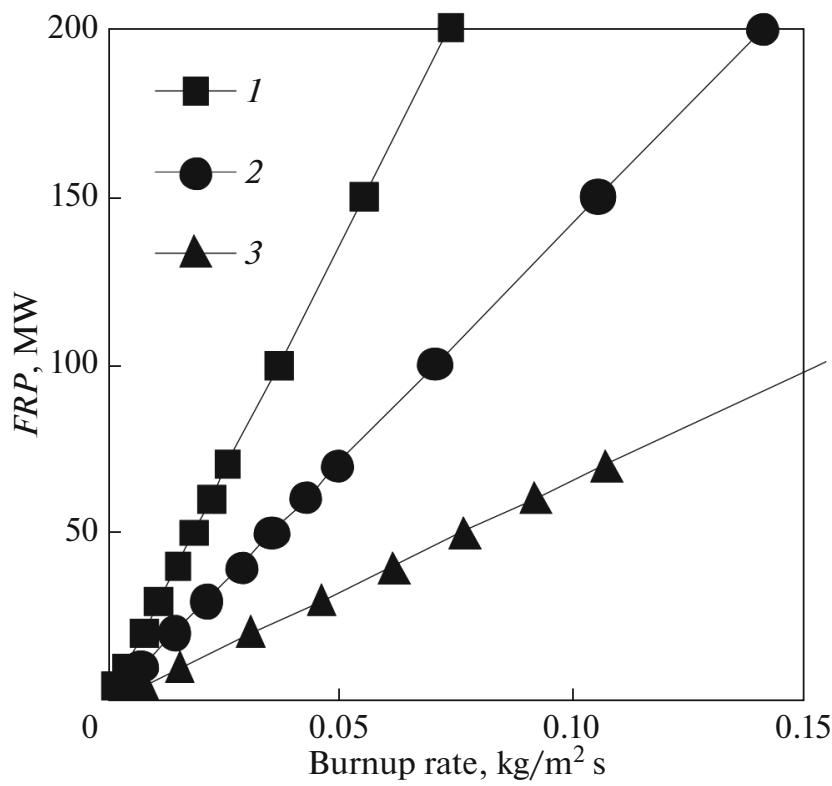

(b)

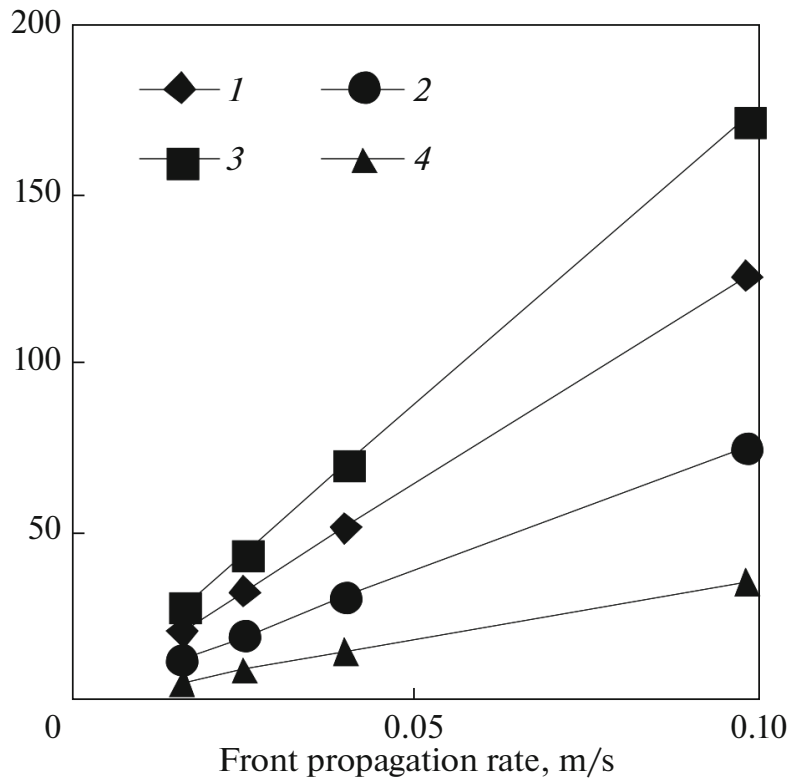

Fig. 3. Variation of recorded $F R P$ from fire parameters in model equations: (a) recorded $F R P$ values depending on the fuel burnup rate $\left(\mathrm{kg} / \mathrm{m}^{2} \mathrm{~s}\right)$ taking into account the area of active combustion in a pixel: (1) $1000 \mathrm{~m}^{2}$, (2) $500 \mathrm{~m}^{2}$, and (3) $250 \mathrm{~m}^{2}$; (b) dependence on the front propagation rate and fuel loads in the active combustion zone $\left(\mathrm{kg} / \mathrm{m}^{2}\right)$ : (1) for $1.5 \mathrm{~kg} / \mathrm{m}^{2}$ and $\beta=0.55$, (2) for $1.5 \mathrm{~kg} / \mathrm{m}^{2}$ and $\beta=0.4$, (3) for $2.5 \mathrm{~kg} / \mathrm{m}^{2}$ and $\beta=0.55$, and (4) for $0.7 \mathrm{~kg} / \mathrm{m}^{2}$ and $\beta=0.4$.

with respect to an increase in the total area of the fire polygon.

The estimates obtained by us (Table 2 ) for direct carbon emissions from Siberian fires were $83 \pm 21 \mathrm{Tg}$ /year, which is on average $17 \%$ lower than the value $112 \pm$ $25 \mathrm{Tg}$ /year obtained using methodology (1) and (2). In the given time interval of 2002-2016, the direct fire emissions varied from minimum values of $20-$ $40 \mathrm{Tg} /$ year $(2004,2005,2007,2009$, and 2010) to the maximum value of $227 \mathrm{Tg} /$ year in 2012 (Fig. 4). Taking into account the confidence interval, this corresponds to the range of limiting values given in studies for various scenarios of regional fire frequency (Glagolev and Sabrekov, 2014; Bondur et al., 2016; Shvidenko et al., 2011; Soja et al., 2004).

Previously, some results have been obtained that describe the burning intensity and the relationship between FRP and the amount of burned biomass for nonforest and experimental fires (Boschetti and Roy, 2009; Kumar et al., 2011). However, for the first time, the approach was implemented to combustion under Siberian conditions. The results obtained by us and the possibility of their wider use in practice, including the near real-time estimation of emissions, are important for understanding the fundamental planetary processes where it is critically important to use the differential approach to the contribution of Siberian fires.

\section{CONCLUSIONS}

The method of fire-intensity parameterization was tested for Siberian conditions on the basis of remote sensing data on the fire radiative power from active burning zones $(F R P)$. For the first time under Siberian conditions, a classification of fire areas was performed taking into account combustion intensity. It has been

Table 2. Long-term average mass of burned fuel and direct carbon fire emissions calculated by methods (1) and (2) and using the proposed technique with (4). Siberian fires for 2002-2016

\begin{tabular}{|c|c|c|c|c|c|c|c|c|c|}
\hline \multirow{2}{*}{$\begin{array}{l}\text { Calculation } \\
\text { method }\end{array}$} & \multicolumn{3}{|c|}{$\begin{array}{c}M \\
\text { long-term average }\end{array}$} & \multicolumn{3}{|c|}{$\begin{array}{c}C \\
\text { long-term average }\end{array}$} & \multicolumn{3}{|c|}{ Relative deviation } \\
\hline & $10^{12} \mathrm{~kg}$ & $\sigma$ & $\begin{array}{c}\text { confidence } \\
\text { interval }(\alpha=0.1)\end{array}$ & $\mathrm{Tg} /$ year & $\sigma$ & $\begin{array}{c}\text { confidence } \\
\text { interval }(\alpha=0.1)\end{array}$ & $\%$ & $\sigma$ & $\begin{array}{c}\text { confidence } \\
\text { interval }(\alpha=0.1)\end{array}$ \\
\hline$(1),(2)$ & 0.192 & 0.131 & 0.067 & 111.9 & 68.4 & 25.4 & 170 & 16 & 00 \\
\hline$(1),(2)$, and (4) & 0.159 & 0.108 & 0.055 & 83.1 & 56.5 & 21.0 & $1 / .3$ & 1.0 & 0.8 \\
\hline
\end{tabular}




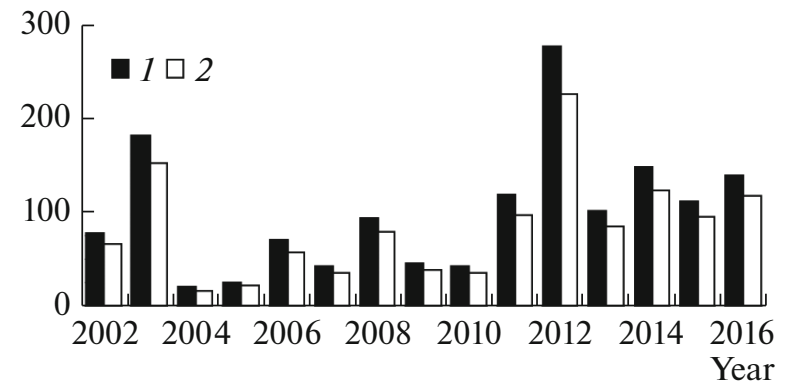

Fig. 4. Variation of direct carbon emissions from Siberian fires in 2002-2016: (1) calculated using standard technique (1) and (2) calculated from remote sensing data on intensity using techniques (1) and (4).

quantitatively established that low-, medium-, and high-intensity fires account for 41.2-58.9, 35.0-46.5, and $6.10-13.44 \%$ of the total area of fires in the season. With an increase in the total area of the fire polygon, a decrease in the fraction of low-intensity combustion sites was observed, and the areas with medium and high values of heat radiation tended to increase.

A technique was developed for calibrating the estimates of the amount of burned fuel and their use in the calculation of direct fire emissions. This approach is based on differential use of the contributions of individual fire sites characterized by variable intensity. For the first time, based on refined instrumental measurement data, estimates for burned fuel $(M)$ and direct fire emissions $(C)$ in Siberia were obtained. The relative deviations of $\Delta M_{\text {rel }}$ and $\Delta C_{\text {rel }}$ were found to be at a level of $14-21 \%$ below the results of calculations obtained with standard approaches.

The estimates for direct emissions from Siberian fires in a time interval of 2002-2016 were on average $83 \pm 21 \mathrm{Tg} /$ year, or $17 \%$ lower than $112 \pm 25 \mathrm{Tg}$ /year, which was obtained using the standard technique. In this case, the recorded range of the variation of direct carbon emissions in different years was $20-227 \mathrm{Tg} /$ year.

\section{ACKNOWLEDGMENTS}

This work was supported by the Russian Foundation for Basic Research, the Government of the Krasnoyarsk Region, and the Krasnoyarsk krai Foundation for Research and Development Support, project no. 17-41-240475.

\section{REFERENCES}

Andreev, Yu.A., Andreev, A.Yu., Mikhailov, P.V., and Pautyak, V.G., and Komorovskii, V.S., Estimating the reserve of forest fuel for state forest inventory, Tr. SPbNII Les. Khoz., 2015, no. 1, pp. 39-46.

Baldocchi, D., Chu, K., and Reichstein, M., Inter-annual variability of net and gross ecosystem carbon fluxes: a review, Agric. Forest Meteorol., 2017, pp. 1-14.

https://doi.org/10.1016/j.agrformet.2017.05.015
Bartalev, S.A., Yegorov, V.A., Ershov, D.V., Isaev, A.S., Lupyan, E.A., and Plotnikov, D.E., Satellite mapping of the vegetative cover of Russia according to the MODIS spectroradiometer, Sovrem. Probl. Distantsionnogo Zondirovaniya Zemli Kosmosa, 2011, vol. 8, no. 4, pp. 285302.

Bartalev, S.A., Stytsenko, F.V., Egorov, V.A., and Lupyan, E.A., Satellite estimation of forest destruction in Russia from fires, Lesovedenie, 2015, no. 2, pp. 83-94.

Bondur, V.G., Gordo, K.A., and Kladov, V.L., Spacetime distributions of wildfire areas and emissions of carboncontaining gases and aerosols in Northern Eurasia according to satellite-monitoring data, Izv., Atmos. Ocean. Phys., 2017, vol. 53, no. 9, pp. 859-874.

Boschetti, L. and Roy, D.P., Strategies for the fusion of satellite fire radiative power with burned area data for fire radiative energy derivation, J. Geophys. Res., 2009, vol. 114, D20302. https://doi.org/10.1029/2008JD011645

Byram, G.M., Combustion of forest fuels, Forest Fire: Control and Use, New York: McGraw-Hill, 1959, pp. 61-89.

Conard, S.G., Sukhinin, A.L., Stocks, B.J., Cahoon, D.R., Davidenko, E.P., and Ivanova, G.A., Determining effects of area burned and fire severity on carbon cycling and emissions in Siberia, Clim. Change, 2002, vol. 55, nos. 1-2, pp. 197-211.

Dozier, J., A method for satellite identification of surface temperature fields of sub-pixel resolution, Remote Sens. Environ., 1981, vol. 11, pp. 221-229.

Giglio, L., MODIS Collection 5 Active Fire Product User's Guide (Version 2.5, 31 March 2013), 2013.

Glagolev, M.V. and Sabrekov, A.F., Answer to A.V. Smagin: II. The carbon balance of Russia, DOSiGIK, 2014, vol. 5, no. 2, pp. 50-69.

de Groot, W.J., Cantin, A.S., Flannigan, M.D., Soja, A.J., Gowman, L.M., and Newbery, A., A comparison of Canadian and Russian boreal forest fire regimes, For. Ecol. Manage, 2013, no. 294, pp. 23-34. https://doi.org/10.1016/j.foreco.2012.07.033

Ichoku, C. and Kaufman, Y.J., A method to derive smoke emission rates from MODIS fire radiative energy measurements, IEEE Trans. Geosci. Remote Sens., 2005, vol. 43, pp. 2636-2649.

Ivanova, G.A., Ivanov, V.A., Kukavskaya, E.A., Conard, S.G., and McRae, D.J., Fire impact on carbon emissions in pine forests of central Siberia, Sib. Ekol. Zh., 2007, vol. 14, no. 6, pp. 885-895.

Ivanova, G.A., Zhila, S.V., Kukavskaya, E.A., and Ivanov, V.A., Post-pyrogenic transformation of the plant phytomass in stands of the lower Angara region, Les. Zh., 2016, no. 6, pp. 17-32. https://doi.org/10.17238/issn0536-1036.2016.6.17

Kasischke, E.S. and Bruhwiler, L.P., Emissions of carbon dioxide, carbon monoxide, and methane from boreal forest fires in 1998, J. Geophys. Res., 2003, no. 108, no. D1, 8146.

https://doi.org/10.1029/2001JD000461

Kukavskaya, E., Soja, A., Petkov, A., Ponomarev, E., Ivanovo, G., and Conard, S., Fire emissions estimates in Siberia: Evaluation of uncertainties in area burned, land cover, and fuel consumption, Can. J. For. Res., 2013, 
vol. 43, no. 5, pp. 493-506.

https://doi.org/10.1139/cjfr-201-0367

Kumar, S.S., Roy, D.P., Boschetti, L., and Kremens, R., Exploiting the power law distribution properties of satellite fire radiative power retrievals: A method to estimate fire radiative energy and biomass burned from sparse satellite observations, J. Geophys. Res., 2011, vol. 116, D19303. https://doi.org/10.1029/2011JD015676

Kurbatskii, N.P. and Ivanova, G.A., Pozharoopasnost' sosnyakov lesostepi $i$ puti ee snizheniya (Fire Hazard of Pines of Forest-Steppes and Its Reduction Ways), Krasnoyarsk: ILiD OS RAN, 1987.

Litvintsev, K.Yu., Amel'chugov, S.P., Gavrilov, A.A., Dekterev, A.A., Negin, V.A., and Kharlamov, E.B., Software package for the numerical simulation of fire dynamics ( $\sigma$ Fire), Certificate no. 2010613073, May 11, 2010.

McRae, D.J., Conard, S.G., Ivanova, G.A., Sukhinin, A.I., Baker, S.P., Samsonov, Y.N., Blake, T.W., Ivanov, V.A., Ivanov, A.V., Churkina, T.V., Hao, W.M., Koutzenogij, K.P., and Kovaleva, N., Variability of fire behavior, fire effects and emissions in scotch pine forests of central Siberia, Mitigation Adapt. Strategies Global Change, 2006, vol. 11, no. 1, pp. 45-74.

https://doi.org/10.1007/s11027-006-1008-4

Menter, E.R., Zonal two equation k-omega turbulence models for aerodynamic flows, 24th AIAA Fluid Dynamics Conference, Orlando, Fla.: AIAA, 1993, 93-2906.

Ponomarev, E.I. and Kharuk, V.I., Wildfire occurrence in forests of the Altai-Sayan region under current climate changes, Contemp. Probl. Ecol., 2016, vol. 9, no. 1, pp. 29-36. https://doi.org/10.1134/S199542551601011X

Ponomarev, E.L. and Shvetsov, E.G., Satellite detection of forest fires and geoinformation methods of data calibration, Issled. Zemli Kosmosa, 2015, no. 1, pp. 84-91. https://doi.org/10.7868/S0205961415010054

Ponomarev, E.L., Kharuk, V.L., and Ranson, I.K., Wildfires dynamics in Siberian larch forests, Forests, 2016, vol. 7, no. 125 , pp. 1-9. https://doi.org/10.3390/f7061025

Ponomarev, E.L., Shvetsov, E.G., and Usataya, Yu.O., Determination of the energy properties of wildfires in siberia by remote sensing, Izv., Atmos. Ocean. Phys., 2018, vol. 54, no. 9, pp. 979-985.

https://doi.org/10.1134/S000143381809030X

Safronov, A.N., Fokeeva, E.V., Rakitin, V.S., Grechko, E.I., and Shumsky, R.A., Severe wildfires near Moscow, Russia in 2010: Modeling of carbon monoxide pollution and comparisons with observations, Remote Sens., 2015, vol. 7 , no. 1 , pp. $395-429$. https://doi.org/10.3390/rs70100395

Seiler, W. and Crutzen, P.J., Estimates of gross and net fluxes of carbon between the biosphere and atmosphere from biomass burning, Clim. Change, 1980, no. 2, pp. 207-247.

https://doi.org/10.1007/BF00137988

Shvidenko, A.Z., Shchepashchenko, D.G., Vaganov, YeA., Sukhinin, A.I., Maksyutov, Sh.Sh., McCallum, I., and Lakyda, I.P., Impact of wildfires in Russia between 1998 and 2010 on ecosystems and the global carbon budget, Dokl. Earth Sci., 2011, vol. 441, no. 2, pp. 1678-1682.

Smith, T.F., Shenand, Z.F., and Friedman, J.N., Evaluation of coefficients for the weighted sum of gray gases model, J. Heat Transfer, 1982, vol. 104, pp. 602-608.

Soja, A.J., Cofer, W.R., Shugart, H.H., Sukhinin, A.I., Stackhouse, P.W., McRae, D.J., and Conard, S.G., Estimating fire emissions and disparities in boreal Siberia (1998-2002), J. Geophys. Res., 2004, vol. 109, D14S06. https://doi.org/10.1029/2004JD004570

Sukhinin, A.J., The system of space monitoring of forest fires in the Krasnoyarsk region, Sib. Ekol. Zh., 1996, vol. T. 3, no. 1, pp. 85-92.

Tsvetkov, P.A., Adaptation of Gmelin larch to fires in northern taiga of Central Siberia, Sib. Ekol. Zh., 2005, no. 1, pp. 117-129.

Valendik, E.N., Sukhinin, A.I., and Kosov, I.V., Vliyanie nizovykh pozharov na ustoychivost' khvoinykh porod (Influence of Grassland Fires on the Stability of Coniferous Species), Krasnoyarsk: IL SO RAN, 2006.

Vermote, E., Ellicott, E., Dubovik, O., Lapyonok, T., Chin, M., Giglio, L., and Roberts, G.J., An approach to estimate global biomass burning emissions of organic and black carbon from MODIS fire radiative power, J. Geophys. Res., 2009, vol. 114, D18205. https://doi.org/10.1029/2008JD011188

Volokitina, A.V. and Sofronov, M.A., Klassifikatsiya i kartografirovanie rastitel'nykh goryuchikh materialov (Classification and Mapping of Vegetable Combustible Materials), Novosibirsk: SO RAN, 2002.

Wooster, M.J., Roberts, G., Perry, G.L.W., and Kaufman, Y.J., Retrieval of biomass combustion rates and totals from fire radiative power observations: FRP derivation and calibration relationships between biomass consumption and fire radiative energy release, J. Geophys. Res., 2005, vol. 110, D24311. https://doi.org/10.1029/2005JD006318

Yurova, A.Yu., Paramonov, A.V., Konovalov, I.B., Kuznetsova, L.N., and Beekmann, M., Forecast of the intensity of thermal radiation and aerosol emission from forest fires in the Central European region, Opt. Atmos. Okeana, 2013, vol. 26, no. 3, pp. 203-207.

Zamolodchikov, D.G., Grabovskii, V.I., and Kraev, G.N., A twenty year retrospective on the forest carbon dynamics in Russia, Contemp. Probl. Ecol., 2011, vol. 4, no. 7 , pp. $706-715$.

Translated by V. Arutyunyan 